\title{
Catalytic conversion of glucose in fructose utilizing high-silica zeolite Sn-ZSM-12
}

\section{(Conversão catalítica de glicose em frutose utilizando zeólita Sn-ZSM-12 de alta sílica)}

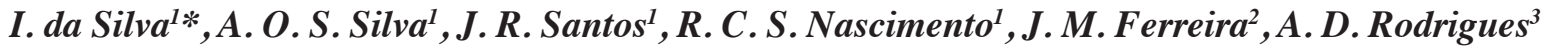 \\ ${ }^{l}$ Federal University of Alagoas, Catalyst Synthesis Laboratory, Campus A.C. Simões, \\ Av. Lourival Melo Mota s/n, 57072-900, Maceio, AL, Brazil \\ ${ }^{2}$ Federal University of Alagoas, Academic Registration and Control Coordination, Penedo, AL, Brazil \\ ${ }^{3}$ Federal University of Alagoas, Biofuels and Energy Laboratory, Maceió, AL, Brazil
}

\begin{abstract}
Tin incorporation in high-silica ZSM-12 zeolite was evaluated using different concentrations of tin and different structure-directing agents (SDA), in order to be used in the glucose isomerization reaction in fructose. The tetraethylammonium hydroxide SDA successfully formed the structure of the high silica zeolite ZSM-12; however, in this system, the addition of Sn prevented the formation of the ZSM-12 zeolite. Therefore, tetraethylammonium bromide was used as SDA, but the syntheses of high-silica ZSM12 zeolite without and with tin incorporation were not effective. Then methyltriethylammonium chloride was used as SDA, and the high-silica ZSM-12 structure was formed only with the incorporation of tin. The samples with ZSM-12 structure and different concentrations of tin were evaluated in reaction of glucose conversion to fructose. It was found that the sample with the lowest tin content $(\mathrm{Sn} / \mathrm{Si}=0.005)$ achieved the highest glucose conversion and the highest fructose yield.
\end{abstract}

Keywords: MTW, zeolites, high-silica, isomerization, sugars.

\section{Resumo}

A incorporação de estanho na zeólita ZSM-12 de alta sílica foi avaliada utilizando diferentes concentrações de estanho e diferentes agentes direcionadores de estrutura (ADS), a fim de ser utilizada na reação de isomerização da glicose para frutose. A síntese com hidróxido de tetraetilamônio como ADS formou a estrutura da zeólita ZSM-12 de alta sílica, entretanto, neste sistema, a adição de Sn impediu a formação da zeólita ZSM-12. Portanto, o brometo de tetraetilamônio foi utilizado como ADS, mas as sínteses com e sem a incorporação de Sn não produziram a zeólita ZSM-12. Em seguida, o cloreto de metiltrietilamônio foi utilizado como ADS e a estrutura ZSM-12 de alta sílica foi formada apenas com a incorporação de estanho. As amostras com estrutura ZSM-12 e diferentes concentrações de estanho foram avaliadas na reação de conversão de glicose em frutose. Verificou-se que a amostra com menor teor de estanho $(\mathrm{Sn} / \mathrm{Si}=0,005)$ obteve a maior conversão de glicose e o maior rendimento de frutose.

Palavras-chave: MTW, zeólitas, alta sílica, isomerização, açúcares.

\section{INTRODUCTION}

The possibility of oil becoming a scarce resource has motivated the search for alternative sources of energy, with emphasis on the use of lignocellulosic biomass. Therefore, most research investigates the production of petroleum products through this source. The big challenge is to produce similar petroleum products utilizing renewable sources. Fructose produced in glucose degradation can be used in industries as a renewable source for the production of raw materials for the manufacture of polymers, drugs, and foods [1]. The glucose isomerization reaction in fructose has greatly expanded due to investigations to convert biomass into energy and petroleum-based chemicals and the large

*ivo.silva@penedo.ufal.br

Dhttps://orcid.org/0000-0002-3134-9999 production of high-fructose corn syrups [2]. Authors report the ease of converting fructose into chemicals due to their high selectivity, getting high yields [3,4]. However, the highcost of fructose makes its use impossible in the industrial scale isomerization reaction [5]. The isomerization reaction of glucose in fructose is an alternative route since glucose is abundant in nature and presents low cost [6].

Due to the properties of high acidity, high thermal stability, and selectivity, zeolites have been successfully used in various catalytic reactions such as catalytic cracking [7], ethanol dehydration reaction [8], hydrogenation reaction [9], oxidation reaction [10], and isomerization reaction [11]. Homogeneous catalysts and zeolites of basic active sites were used in the isomerization reaction of the glucose in fructose and were not successful [12, 13]. Heterogeneous acid site catalysts have high selectivities and yields in the isomerization reaction of the glucose in fructose [14]. In 
addition to acid sites, another feature of zeolites that perform optimally in isomerization reaction of the glucose in fructose is pore size. Large pore zeolites demonstrated better performance in isomerization reactions than medium pore zeolites. Conversely, the mesoporous materials presented little activity of glucose isomerization [2].

Research demonstrates that tin(IV), when incorporated into the zeolite structure, has an active acid character center for isomerizing aldoses and demonstrated better performance among metals for isomerization reaction of the glucose in fructose $[2,15]$. ZSM-12 or MTW is considered a large pore zeolite [16], so the present research synthesized Sn(IV) in the structure of high-silica ZSM-12 zeolite and evaluated different concentrations of tin in the catalyst applying in the glucose isomerization reaction in fructose at $120^{\circ} \mathrm{C}$ at different reaction times. The catalysts were characterized by X-ray diffractometry (XRD), thermal analysis (TG/DTG), $\mathrm{N}_{2}$ physisorption, scanning electron microscopy (SEM), and energy-dispersive X-ray fluorescence spectroscopy (EDX). Glucose and fructose were quantified by high-performance liquid chromatography (HPLC).

\section{MATERIALS AND METHODS}

Reagents: the following reagents were used as sources of inorganic materials: sodium metasilicate hydrate $(24.5 \%$ $\mathrm{Na}_{2} \mathrm{O}, 47.5 \% \mathrm{SiO}_{2}$, Carlo Erba), silica gel (93\%, Merck), tetraethyl orthosilicate (98\%, Aldrich), and sodium hydroxide (99\%, Merck). The structure-directing agents (SDA) evaluated were: solution of tetraethylammonium hydroxide (40\% in water, Sigma-Aldrich), methyltriethylammonium chloride (97\%, Sigma), and tetraethylammonium bromide (98\%, Aldrich). The carbohydrates glucose (99\%, Exodo) and fructose (99\%, Sigma) were used in experiments to evaluate catalytic activity.

Synthesis of high-silicazeolite ZSM-12: by ahydrothermal method, employing the tetraethylammonium hydroxide (TEAOH) as SDA and without adding seed crystals. The synthesis methodology was similar to that reported in [17]. The procedure for preparing the reaction mixture used in the synthesis consisted of the following steps: 1) sodium metasilicate was solubilized in $30 \%$ of the water required for synthesis; 2) addition of the TEAOH solution, followed by stirring for $3 \mathrm{~h} ; 3$ ) the silica gel was dispersed in the remaining $70 \%$ of the water; and 4 ) the solution obtained in step 2 was added slowly to the dispersion formed by silica gel in water, followed by $3 \mathrm{~h}$ of stirring. The hydrogel formed was separated into several portions, transferred to stainless steel autoclaves lined with polytetrafluoroethylene (PTFE), and hydrothermally treated at $175{ }^{\circ} \mathrm{C}$ under autogenous pressure in static conditions for $10 \mathrm{~h}$.

Synthesis of Sn-ZSM-12 zeolite: the adaptation of the synthesis method reported in [17] for the crystallization of high-silica zeolites ZSM-12 with the incorporation of tin in the structure resulted in the formation of a mixture of $\alpha$-quartz and magadiite, instead of materials with the MTW structure containing Sn (Sn-ZSM-12). Thus, another methodology was necessary to synthesize this type of material. The study [18] describes the methodology of the synthesis of high-silica ZSM-12 with tin incorporation in the crystalline structure, using a highly specific SDA, synthesized in a laboratory, identified as 1,6-hexamethylenebis(benzyl hydroxide dimethyl ammonium). This methodology was adapted here, replacing the SDA reported in [18] with the commercial SDAs tetraethylammonium bromide (TEABr) and methyltriethylammonium chloride (MTEACl), as an attempt to synthesize Sn-ZSM-12 more easily and economically. The procedures for obtaining the synthesis gels consisted of the following steps: 1) sodium hydroxide was solubilized in $30 \%$ of the water required for synthesis; 2) TEABr or MTEACl was dissolved in $30 \%$ of the water required and added a solution from step 1, followed by stirring for $1 \mathrm{~h}$; 3 ) the tetraethyl orthosilicate was added to form a hydrogel, followed by stirring for $3 \mathrm{~h} ; 4)$ the tin source $\left(\mathrm{SnCl}_{4} .5 \mathrm{H}_{2} \mathrm{O}\right)$ was dissolved in $30 \%$ of the water required in the synthesis; and 5) the seed crystals were dispersed in the remaining $10 \%$ of the water and added to the gel formed in step 4 and stirred for $30 \mathrm{~min}$. The reactional mixture resultant was divided into several portions, transferred to stainless steel autoclaves lined with PTFE, and hydrothermally treated at $160{ }^{\circ} \mathrm{C}$, under autogenous pressure in static conditions, for periods of 24 to $96 \mathrm{~h}$. Other synthesis experiments were carried out to obtain materials with varying $\mathrm{Sn} / \mathrm{Si}$ molar ratio. These materials had the following molar gel composition: 0.133 $\mathrm{R}: \mathrm{SnO}_{2}: 0.117 \mathrm{Na}_{2} \mathrm{O}: 30 \mathrm{H}_{2} \mathrm{O}$, with $\mathrm{R}=\mathrm{TEABr}$ or MTEACl and $\mathrm{x}=0.005,0.010$, and 0.015 .

Product recovery after crystallization: after the reaction time in the oven, the autoclaves were cooled to room temperature. The solid resulting from the crystallization process was separated from the supernatant by vacuum filtration, washed several times with distilled water (to neutral $\mathrm{pH}$ ), and dried at $100{ }^{\circ} \mathrm{C}$ for $24 \mathrm{~h}$. Calcination of samples: the samples, before adsorption analysis and catalytic evaluation, were calcined using the following procedure: i) initially subjected to a heating rate of $2{ }^{\circ} \mathrm{C} \cdot \mathrm{min}^{-1}$ from room temperature to $450{ }^{\circ} \mathrm{C}$ in a dynamic atmosphere of air (400 $\mathrm{mL} \cdot \mathrm{min}^{-1}$ ); and ii) after reaching $450{ }^{\circ} \mathrm{C}$, it was kept under these conditions for $4 \mathrm{~h}$. This final calcination temperature was defined based on the thermal decomposition data of the samples obtained by thermogravimetry.

Physicochemical characterizations: the synthesized samples were initially characterized by XRD technique. These results were used as a qualitative way of identifying the formed zeolitic phases and the presence or not of contaminating materials. The samples with the highest crystallinity were characterized by complementary techniques of thermal analysis (TG/DTG), $\mathrm{N}_{2}$ physisorption, $\mathrm{X}$-ray fluorescence, and scanning electron microscopy (SEM).

Catalytic conversions of glucose: the reactions were conducted in PTFE pots inserted into stainless steel autoclaves. These vessels were placed in a device installed inside an oven (Tecnal, TE028), which allowed rotation by rolling at $60 \mathrm{rpm}$. The reaction was conducted at $120^{\circ} \mathrm{C}$, and 
the progress of the reaction was analyzed by taking samples at intervals of 1,2 , and $3 \mathrm{~h}$. After the pre-established reaction time, the autoclave was removed from the oven and cooled to room temperature. Then the reaction mixture was centrifuged at $2500 \mathrm{rpm}$ for $10 \mathrm{~min}$. The liquid mixture was analyzed on HPLC to determine the concentration of glucose and products formed. In the catalytic selection tests, the reaction mixture was composed of $10 \mathrm{~mL}$ of $5 \mathrm{wt} \%$ glucose aqueous solution and $0.1 \mathrm{~g}$ of catalyst. An additional experiment was also carried out using the same solution containing 5 wt $\%$ glucose, but without the addition of a catalyst. Based on the results of fructose yield, the catalyst with the highest activity was selected to perform additional experiments with glucose solutions of concentrations of 10, 20, and $40 \mathrm{wt} \%$. Characterization and quantification of reaction products: the liquid mixture recovered from the autoclave was filtered through a Millipore $0.45 \mu \mathrm{m}$ pore size membrane and then injected into a high-performance liquid chromatograph (HPLC, Shimadzu, UFLC) containing a refractive index detector (RID). The chromatograph was equipped with a pump (Shimadzu, LC 20AD SP), an automatic $20 \mu \mathrm{L}$ loop injector, and was operated at an isocratic method. The chromatographic column utilized for the determination of the carbohydrates was a Shodex Sugar SC1011 (8.0x300 $\mathrm{mm}$ ), operating under the following conditions: $80^{\circ} \mathrm{C}$, mobile phase ultra-pure Milli-Q water with a flow rate of 1 $\mathrm{mL} / \mathrm{min}$, and run time of $20 \mathrm{~min}$.

\section{RESULTS AND DISCUSSION}

The main results obtained from the synthesis and characterization of zeolites ZSM-12 and Sn-ZSM-12 with different $\mathrm{Sn} / \mathrm{Si}$ ratios and the application of catalysts in isomerization reaction of the glucose in fructose is presented and discussed, highlighting the conversion rate, selectivity, and yield.

$X$-ray diffractometry: XRD was utilized as the main characterization technique to samples in as-synthesized form, because it detected whether or not the sample originated the desired crystalline phase. When the formation of the desired zeolitic phase was verified, additional characterizations were performed by other techniques. Fig. 1 shows the X-ray diffractograms of the high-silica samples ZSM-12 and Sn-ZSM-12 synthesized with different SDAs. It appears that the high-silica ZSM-12, synthesized according to the methodology presented in [17], using TEAOH as SDA (Fig. 1a), presented the main diffraction peaks at positions and intensities similar to those reported for a typical sample of ZSM-12 in the structure database of International Zeolite Association [19]. This indicated that there was the formation of zeolite ZSM-12 as the only crystalline phase, but there was no formation of the ZSM-12 phase in the experiments with tin addition using TEAOH as SDA. New syntheses were performed for the crystallization of ZSM-12 and Sn-ZSM-12 replacing TEAOH with TEABr, but the use of this SDA also did not result in the formation of the zeolite ZSM-12 and SnZSM-12, as evidenced by the diffractograms shown in Figs.
$1 \mathrm{~b} 1$ and $1 \mathrm{~b} 2$. Other experiments using MTEACl as SDA (Fig. 1c) resulted in a material with peaks possibly related to ZSM-12, but of low intensity that indicated the presence of large amounts of amorphous phases. A more detailed analysis of the diffractograms of the samples that did not produce the pure ZSM-12 phase (Figs. 1b1, 1b2, and 1c), allowed to identify peaks related to other crystalline phases. In the samples with TEAOH as SDA (Figs. $1 b 1$ and 1b2), a peak attributed to the condensed $\alpha$-quartz phase (JCPDS 461045) was identified. The tin-containing sample showed still additional diffraction peaks attributed to the lamellar phase kenyaite (JCPDS 20-1157). In the sample with MTEACl (Fig. 1c), it was possible to identify an additional peak related to the lamellar phase magadiite (JCPDS 42-1350).

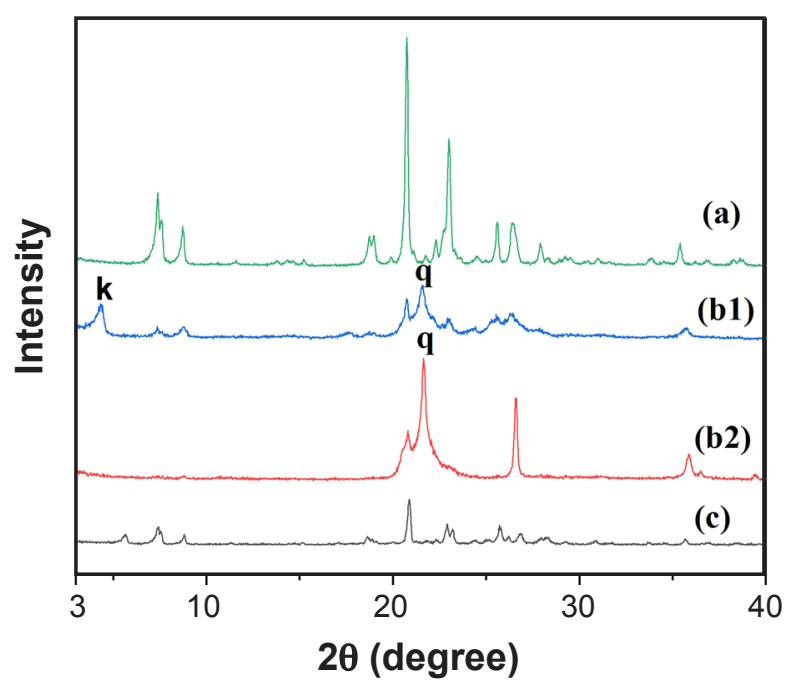

Figure 1: XRD profiles of the synthesized high-silica ZSM12 zeolite samples using as SDA TEAOH (a), TEABr (b1), and MTEACl (c), and Sn-ZSM-12 sample with $\mathrm{Sn} / \mathrm{Si}=0.010$ using TEABr as SDA (b2). k - kenyaite; q - $\alpha$-quartz.

[Figura 1: Perfis de DRX das amostras de zeólitas ZSM-12 de alta sílica utilizando como agentes direcionadores de estruturas (ADS) TEAOH (a), TEABr (b1) e MTEACl (c), e amostra Sn-ZSM-12 com $\mathrm{Sn} / \mathrm{Si}=0,010$ usando TEABr (b2). $k$ - kenyaita, $q$ - quartzo- $\alpha$.]

Yoo et al. [20] reported the synthesis of ZSM-12 utilizing TEABr as SDA and concluded that the structure formed was similar to the structure of zeolite ZSM-12 obtained with $\mathrm{TEAOH}$ as SDA. The influence of the $\mathrm{OH} / \mathrm{SiO}_{2}$ ratio on the crystallization of ZSM-12 was established for samples containing aluminum [20], but this behavior may be different in our syntheses. The reaction medium used here did not contain $\mathrm{Al}$ and aimed to obtain high-silica ZSM12 zeolites with the incorporation of $\mathrm{Sn}$ in the structure. Since the synthesis of ZSM-12 from tin-containing gels employing TEABr as SDA was not effective, new syntheses were performed using MTEACl as SDA. In these tests, it was possible to verify that the Sn-ZSM-12 sample presented typical reflections of the zeolite ZSM-12 (Fig. 2). Additional experiments to produce high-silica ZSM-12 without Sn impregnation utilizing MTEACl under the same molar ratio, time, and temperature conditions as Sn-ZSM-12 zeolite 
were unsuccessful. Even with variations in crystallization time, contamination by the kenyaite lamellar phase (JCPDS 20-1157) still occurred at 144 and $168 \mathrm{~h}$, while with $48 \mathrm{~h}$ of treatment, there was no formation of crystalline phases (Fig. 2).

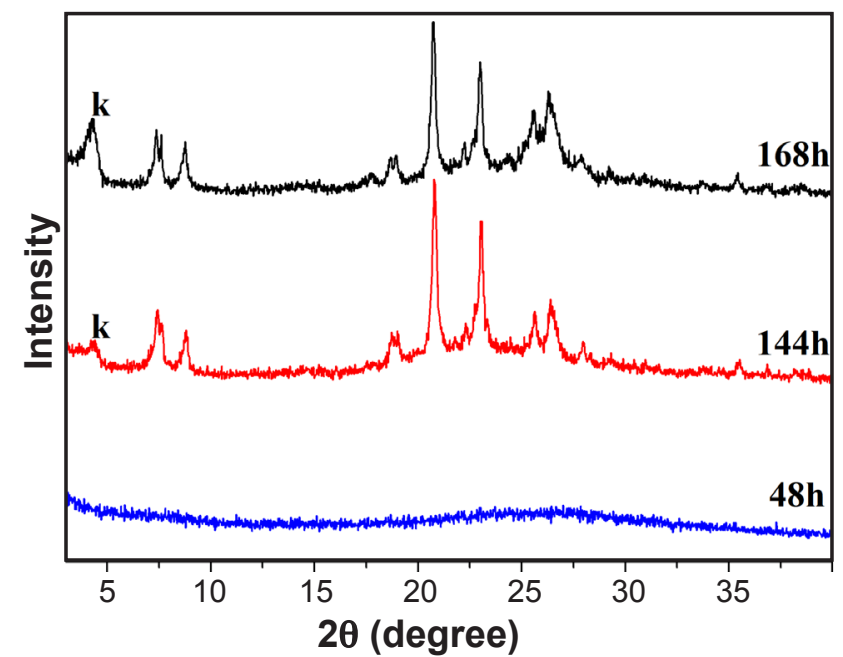

Figure 2: XRD profiles of the samples of high-silica ZSM-12 crystallized at different times with $\mathrm{MTEACl}$ as SDA.

[Figura 2: Perfis de DRX das amostras de ZSM-12 de alta sílica cristalizadas em diferentes tempos com MTEACl como ADS.]

Figs. 3a to 3c show the X-ray diffractograms of samples synthesized with different $\mathrm{Sn} / \mathrm{Si}$ ratios using MTEACl as SDA. The highest crystallinity was observed in the sample with an $\mathrm{Sn} / \mathrm{Si}$ molar ratio of 0.005 (Fig. 3a). The increase of the concentration of tin in the synthesis gel (increasing the $\mathrm{Sn} / \mathrm{Si}$ ratio) caused a reduction in the degree of crystallinity of the sample obtained. This was evidenced by the decrease in the intensity of the diffraction peaks (Figs. $3 b$ and $3 c$ ) and indicated that the incorporation of tin in the ZSM-12 zeolite network is a difficult process, being possible only in low concentrations. Although all samples showed typical peaks of the ZSM-12, an additional peak was also observed (marked with $\mathrm{m}$ in Fig. 3), which was related to a contaminating phase identified as magadiite (JCPDS 42-1350). Figs. 3d to 3f show the X-ray diffractograms of Sn-ZSM-12 samples obtained with MTEACl as SDA after the calcination process to remove MTEACl. The main modification observed in relation to the samples in the non-calcined form was the disappearance of the peak of the magadiite contaminating phase. This was already expected since magadiite has low thermal stability, and when heated to high temperatures, its structure collapses and converts to amorphous materials.

The first report of Sn incorporation in high-silica zeolite ZSM-12 was described by Mal et al. [18], researching the oxidation reaction of phenol, cresol, and xylene in $\mathrm{H}_{2} \mathrm{O}_{2}$ solution. In the same year (1995), Mal et al. [21] evaluated the incorporation of tin in zeolites ZSM-12, MFI, and MEL, for the oxidation reaction of phenol, toluene, cresol, xylene, naphthalene, and 2-methylnaphthalene. Since then, there have been few reports of $\mathrm{Sn}$ incorporation in zeolite
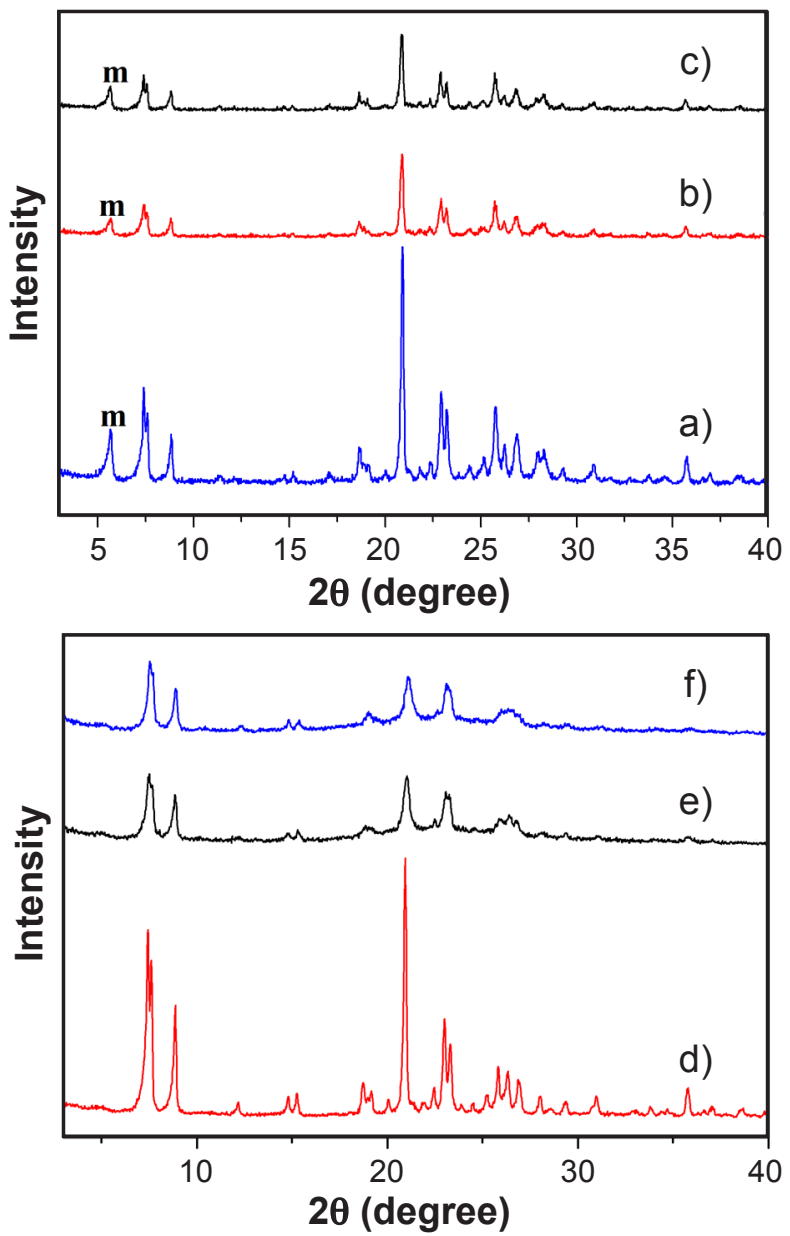

Figure 3: XRD profiles of the non-calcined (a-c) and calcined (df) samples of Sn-ZSM-12 synthesized with MTEACl as SDA and containing different $\mathrm{Sn} / \mathrm{Si}$ molar ratios: a,d) 0.005 ; b,e) 0.010 ; and c,f) 0.015. m - magadiite.

[Figura 3: Perfis de DRX das amostras não calcinadas (a-c) e calcinadas (d-f) de Sn-ZSM-12 sintetizadas com MTEACl como ADS e contendo diferentes razões molares $\mathrm{Sn} / \mathrm{Si}:$ a,d) 0,$005 ; b, e)$ 0,010; e c,f) 0,015. m - magadiita.]

ZSM-12. However, tin has been incorporated into other zeolites to perform catalytic conversions. Jennings et al. [22] incorporated tin into the beta zeolite to apply to lignin depolymerization reactions. Bayu et al. [23] impregnated tin in high-silica beta zeolite utilizing tin chloride and choline chloride and applied in the glucose isomerization reaction.

Thermogravimetric analysis (TG/DTG): Fig. 4 shows the TG/DTG curves of the high-silica ZSM-12 zeolite obtained with TEAOH at $10 \mathrm{~h}$ of crystallization and SnZSM-12 samples synthesized with MTEACl as SDA and different concentrations of tin. In the samples of SnZSM-12 synthesized with MTEACl, the crystallization time was $96 \mathrm{~h}$. In the case of high-silica ZSM-12 sample, the mass derived curve (DTG) indicated that the TEAOH decomposition reaction (event II) occurred in a single step; the event I represented the removal of water on the external surface and inside the pores of the zeolite, whereas event II was attributed to the slow oxidation of carbonaceous compounds (coke) formed from the decomposition of the 
SDA. For samples containing tin, it was observed that the decomposition of MTEACl occurred in a single step (event II) in a similar way to that observed in the case of TEAOH for the sample of high-silica ZSM-12. Event III attributed to the removal of coke also showed similar behavior in both materials. On the other hand, the event I associated with the removal of water from the structure showed very different behavior in the samples with tin, with an intense peak being observed in the DTG curve that indicated an outflow of larger amounts of water. This can be confirmed by the mass loss data shown in Table I related to this event. The low amount of water released by the high-silica ZSM-12 sample is typical of siliceous zeolitic materials, such as silicalite, and indicated that these have a highly hydrophobic surface.

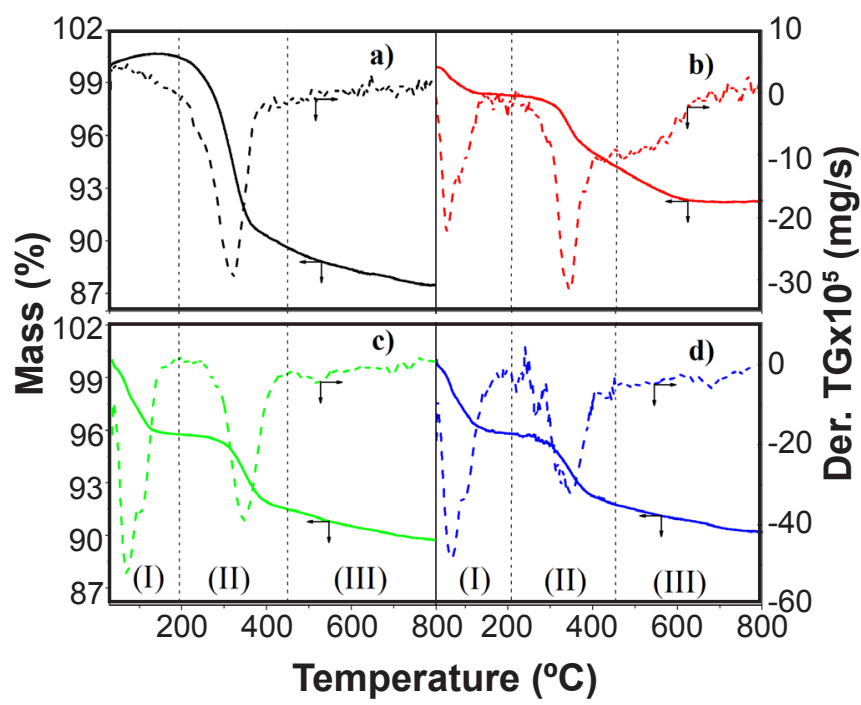

Figure 4: TG/DTG curves of the sample high-silica ZSM-12 (a) and samples of Sn-ZSM-12 synthesized with MTEACl as SDA and $\mathrm{Sn} / \mathrm{Si}$ molar ratio of 0.005 (b), 0.010 (c), and 0.015 (d).

[Figura 4: Curvas de TG/DTG da amostra ZSM-12 de alta sílica (a) e das amostras Sn-ZSM-12 sintetizadas com MTEACl como ADS e razão molar Sn/Si de 0,005 (b), 0,010 (c) e 0,015 (d).]

The TG curves of the high-silica ZSM-12 of our study seem to differ from the results reported by Kasunič et al. [24], who chose a calcination temperature of $550{ }^{\circ} \mathrm{C}$ to remove TEAOH from the zeolite structure. However, their samples have different chemical compositions than those synthesized in our study. Results similar to those obtained in our study were reported in [25] even for samples of different chemical composition and obtained with others crystallization time. The analysis of the TG curves of the samples of Sn-ZSM-12 containing different tin concentrations indicated that the addition of tin occasioned reduction in the total mass loss (Table I) probably due to the increase in structural defects caused by the incorporation of tin in the structure. Knudsen et al. [26] reported the incorporation of tin in the ferrierite, mordenite, and silicalite zeolites in different molar ratios (0.001, 0.005, and 0.01) and concluded that the higher tin concentration caused lower mass loss due to the formation of tin oxide and chloride due to excess tin on the surface of the zeolites.

Determination of specific surface area and pore volume: the adsorption and desorption isotherms of the samples of high-silica ZSM-12 and Sn-ZSM-12 were obtained with $\mathrm{P} / \mathrm{P}_{0}$ ranging from 0.01 to 1 (Fig. 5). The adsorption/ desorption isotherms of all samples were identified as being type I according to the IUPAC classification, which

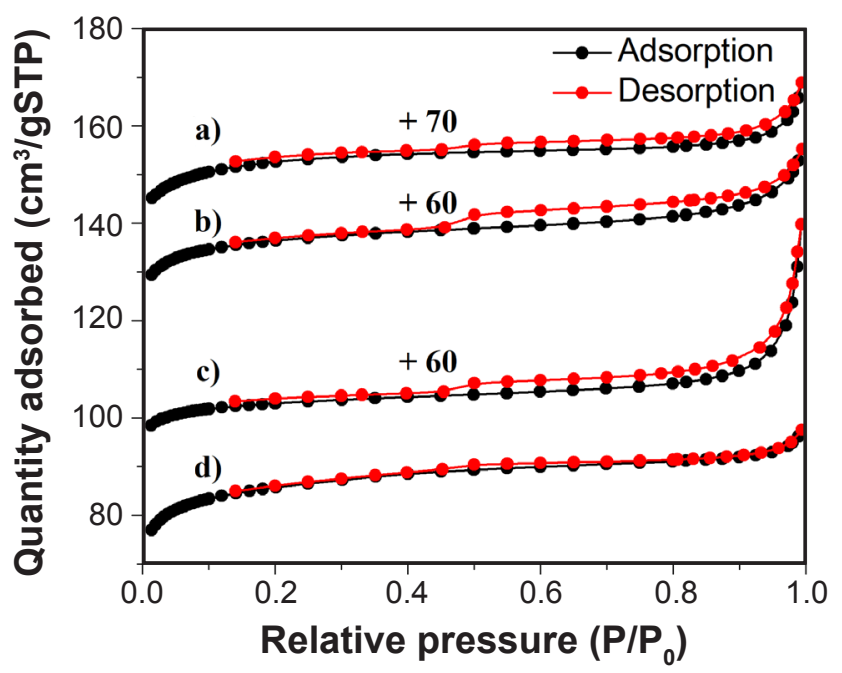

Figure 5: Isotherms of $\mathrm{N}_{2}$ adsorption/desorption at $-196{ }^{\circ} \mathrm{C}$ of the samples high-silica ZSM-12 (a) and Sn-ZSM-12 with Sn/Si of 0.005 (b), 0.010 (c), and 0.015 (d).

[Figura 5: Isotermas de adsorção/dessorção de $N_{2}$ a $-196{ }^{\circ} \mathrm{C}$ das amostras ZSM-12 de alta sílica (a) e Sn-ZSM-12 com Sn/Si de $0,005(b), 0,010(c)$ e 0,015 (d).]

Table I - Thermal events and mass loss quantification of the samples high-silica ZSM-12 and Sn-ZSM-12 with different Sn concentration.

[Tabela I - Eventos térmicos e quantificação da perda de massa das amostras ZSM-12 de alta sílica e Sn-ZSM-12 com diferentes concentrações de Sn.]

\begin{tabular}{ccccccccc}
\hline \multirow{2}{*}{ Sample } & \multirow{2}{*}{$\mathrm{Sn} / \mathrm{Si}$} & \multicolumn{4}{c}{ Temperature range $\left({ }^{\circ} \mathrm{C}\right)$} & \multicolumn{2}{c}{ TG (wt\%) } & \multicolumn{2}{c}{$\Sigma$} \\
& & I & II & III & I & II & III & (wt\%) \\
\hline ZSM-12 & - & $30-190$ & $190-445$ & - & 1.0 & 9.0 & 1.6 & 11.6 \\
Sn-ZSM-12a & 0.005 & $30-210$ & $210-460$ & $410-670$ & 1.3 & 3.1 & 2.9 & 7.3 \\
Sn-ZSM-12b & 0.010 & $30-190$ & $190-445$ & $445-555$ & 4.0 & 4.5 & 1.3 & 9.8 \\
Sn-ZSM-12c & 0.015 & $30-210$ & $210-460$ & $410-455$ & 4.0 & 4.5 & 1.3 & 9.8 \\
\hline
\end{tabular}


is characteristic of microporous materials. But the sample of high-silica ZSM-12 presented type $\mathrm{H} 4$ hysteresis loop, while the samples containing tin presented hysteresis loop that can be classified as type $\mathrm{H} 3$, indicating pores of the type wedge-shaped, cone-shaped, or parallel-plated. Table II summarizes the data of specific surface area obtained by Brunnauer-Emmet-Teller method $\left(\mathrm{A}_{\mathrm{BET}}\right)$, external area $\left(\mathrm{A}_{\text {ext }}\right)$, microporous area $\left(\mathrm{A}_{\text {micro }}\right)$, total volume $\left(\mathrm{V}_{\mathrm{t}}\right)$, microporous volume $\left(\mathrm{V}_{\text {micro }}\right)$, and mesoporous volume $\left(\mathrm{V}_{\text {meso }}\right)$ from the samples ZSM-12 and Sn-ZSM-12. The high-silica ZSM-12 sample presented a typical surface area of the conventional ZSM-12 zeolite. The samples containing tin presented a reduction of surface area, external area, and microporous area in relation to ZSM-12 sample; however, the microporous volume of $0.11 \mathrm{~cm}^{3} \cdot \mathrm{g}^{-1}$ from the samples in this research was similar to the values reported in the literature for the zeolite ZSM-12 [27, 28].

Scanning electron microscopy: SEM micrographs of the high-silica zeolite ZSM-12 synthesized with silica gel and sodium metasilicate as silica source, using TEAOH as SDA are shown in Fig. 6. Fig. 6a shows that the material had the appearance of uniform smooth agglomerated of flake-shaped crystals. However, at higher magnification (Fig. 6b), a more homogeneous aspect was observed, containing well-defined crystals with the appearance of hard and brittle structure revealing overlapping plates of regular size. SEM micrographs of samples of Sn-ZSM-12 with different $\mathrm{Sn} / \mathrm{Si}$ ratios using MTEACl as SDA are shown in Fig. 7. Some features visualized in the samples of ZSM-12 of our study revealed different shapes and textures reported
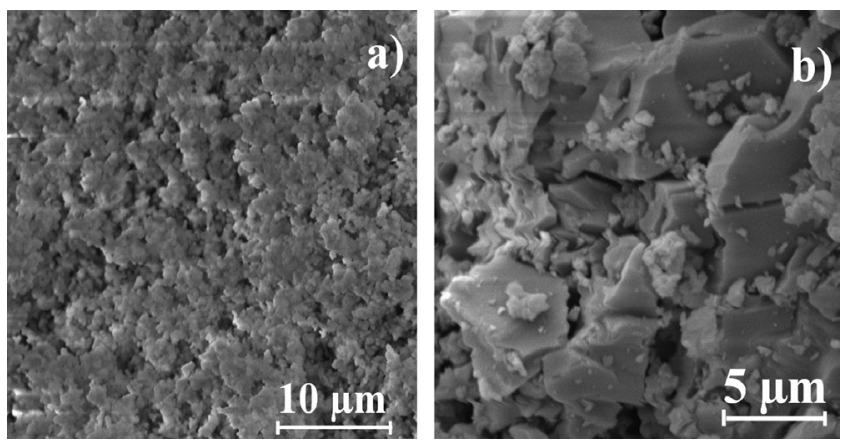

Figure 6: SEM images of the sample high-silica ZSM-12 synthesized with TEAOH as SDA.

[Figura 6: Imagens de MEV da amostra ZSM-12 de alta sílica sintetizada com TEAOH como ADS.]
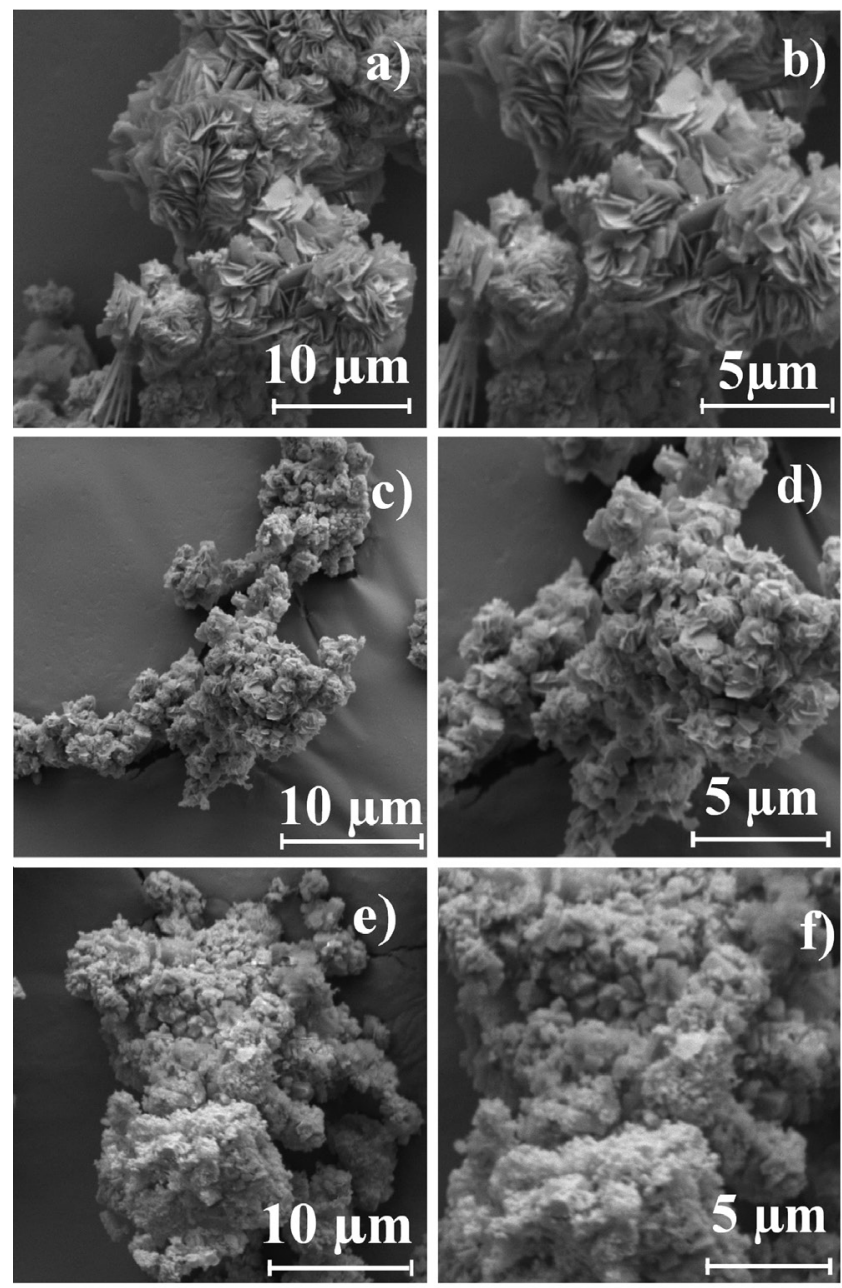

Figure 7: SEM micrographs of the samples Sn-ZSM-12 with different Sn/Si molar ratio: a,b) 0.005; c,d) 0.010; and e,f) 0.015 .

[Figura 7: Imagens de MEV das amostras Sn-ZSM-12 com diferentes razões molares $\mathrm{Sn} / \mathrm{Si}$ : a,b) 0,005; c,d) 0,010; e e,f) 0,015.]

by Masoumifard et al. [29], who utilized the same SDAs (TEAOH and MTEACl), but modified the sources of silica using TEOS, colloidal silica, and silica gel. These results demonstrated that different sources of silica and different SDA modify the shape of the ZSM-12 crystals obtained.

Energy-dispersive X-ray fluorescence spectroscopy: EDX results of the samples ZSM-12 and Sn-ZSM-12 with different tin ratios are shown in Table III. The results of

Table II - Textural properties of the samples high-silica ZSM-12 and Sn-ZSM-12 with different Sn concentration.

[Tabela II - Propriedade texturais das amostras ZSM-12 de alta sílica e Sn-ZSM-12 com diferentes concentrações de Sn.]

\begin{tabular}{cccccccc}
\hline Sample & $\mathrm{Sn} / \mathrm{Si}$ & $\begin{array}{c}\mathrm{A}_{\mathrm{BET}} \\
\left(\mathrm{m}^{2} \cdot \mathrm{g}^{-1}\right)\end{array}$ & $\begin{array}{c}\mathrm{A}_{\text {ext. }} \\
\left(\mathrm{m}^{2} \cdot \mathrm{g}^{-1}\right)\end{array}$ & $\begin{array}{c}\mathrm{A}_{\text {micro }} \\
\left(\mathrm{cm}^{3} \cdot \mathrm{g}^{-1}\right)\end{array}$ & $\begin{array}{c}\mathrm{V}_{\mathrm{t}} \\
\left(\mathrm{cm}^{3} \cdot \mathrm{g}^{-1}\right)\end{array}$ & $\begin{array}{c}\mathrm{V}_{\text {micro }} \\
\left(\mathrm{cm}^{3} \cdot \mathrm{g}^{-1}\right)\end{array}$ & $\begin{array}{c}\mathrm{V}_{\text {meso }} \\
\left(\mathrm{cm}^{3} \cdot \mathrm{g}^{-1}\right)\end{array}$ \\
\hline ZSM-12 & - & 326 & 48 & 278 & 0.14 & 0.11 & 0.03 \\
Sn-ZSM-12a & 0.005 & 190 & 18 & 172 & 0.09 & 0.07 & 0.02 \\
Sn-ZSM-12b & 0.010 & 291 & 37 & 254 & 0.14 & 0.10 & 0.04 \\
Sn-ZSM-12c & 0.015 & 314 & 41 & 273 & 0.14 & 0.11 & 0.03 \\
\hline
\end{tabular}



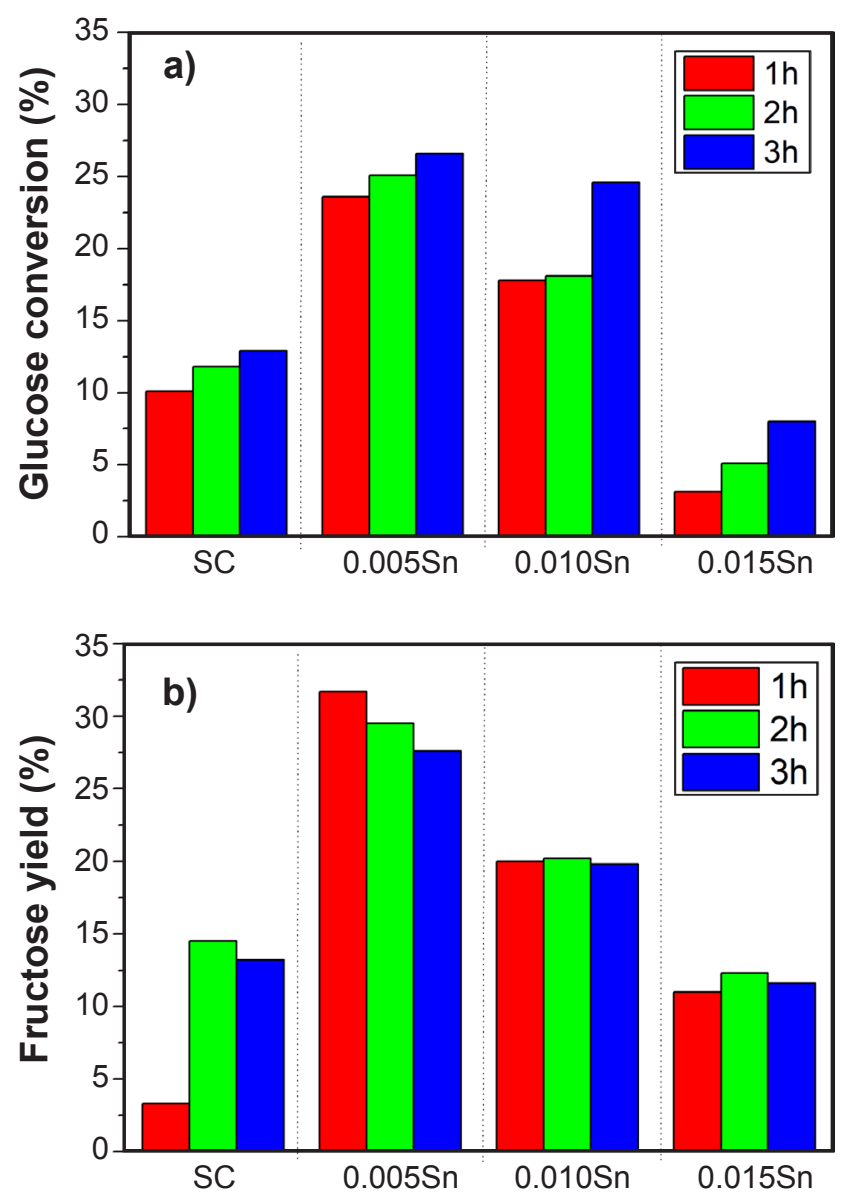

Figure 8: Glucose conversion (a) and fructose yield (b) from $5 \mathrm{wt} \%$ glucose solution in the absence (SC) and presence of catalysts with different tin concentrations at $120{ }^{\circ} \mathrm{C}$ at 3 reaction times.

[Figura 8: Conversão da glicose (a) e rendimento de frutose (b) a partir de solução de 5\% em massa de glicose na ausência (SC) e na presença de catalisadores com diferentes concentrações de estanho a $120{ }^{\circ} \mathrm{C}$ em 3 tempos de reação.]

the element ratio analysis confirmed the presence of tin in the samples of Sn-ZSM-12. A sample containing a higher tin ratio had a higher proportion of $\mathrm{Sn}$ content in the solid phase; a similar result was also reported in [26].

Catalytic conversions of glucose: the results obtained from glucose conversion, in the absence and presence of catalysts prepared with different tin concentration, are shown in Fig. 8a. The reactions were performed at $120{ }^{\circ} \mathrm{C}$ at 3 different reaction times. The glucose concentration used was $5 \mathrm{wt} \%$. The samples containing $\mathrm{Sn} / \mathrm{Si}=0.005$ showed higher glucose conversion than the other samples with higher concentrations of tin and without a catalyst. The highest glucose conversions were observed in the longest reaction time, indicating that the reaction may not yet have reached equilibrium. Increasing the tin concentration in the catalysts led to a reduction in glucose conversion. This fact was confirmed to sample $\mathrm{Sn}-\mathrm{ZSM}-12 \mathrm{c}(\mathrm{Sn} / \mathrm{Si}=0.015)$, which presented lower glucose conversion than the samples with the other catalysts and without a catalyst.
Table III - Quantification by EDX of the elements present in samples ZSM-12 and Sn-ZSM-12.

[Tabela III - Quantificação por EDX dos elementos presentes nas amostras ZSM-12 e Sn-ZSM-12.]

\begin{tabular}{ccc}
\hline Sample & Si $(\%)$ & Sn $(\%)$ \\
\hline ZSM-12 & 97.7 & nd \\
Sn-ZSM-12a & 96.6 & 0.32 \\
Sn-ZSM-12b & 97.3 & 1.14 \\
Sn-ZSM-12c & 93.7 & 3.44 \\
\hline nd - not detected. & &
\end{tabular}

Products formed in the glucose isomerization process: Fig. 8b shows the results of fructose yield for the different catalysts evaluated and the system without a catalyst. The incorporation of tin at the $\mathrm{Sn} / \mathrm{Si}$ molar ratio of 0.005 in zeolite ZSM-12 caused a significant increase in fructose production, but as the tin concentration increased in the catalyst, the fructose yield dropped sharply. Even with the significant increase in fructose yield when using the Sn-ZSM-12a zeolite as a catalyst, the obtained yield was considered low to an industrial scale use; however, conditions can be optimized to obtain better results. Saravanamurugan et al. [30] using the zeolites Y, H-USY, and H-beta to convert the glucose from solutions of $3 \%$ and $1.5 \%$ of glucose in water and water/ethanol mixture $(1: 1)$ achieved yields of $16 \%$ to $40 \%$ of fructose when using zeolite Y, $28 \%$ to $30 \%$ using zeolite H-USY, and $23 \%$ to $40 \%$ fructose using zeolite H-beta. Bermejo-Deval et al. [31] reported that, when incorporating $\mathrm{Sn}$ in the beta zeolite, a yield of $10.3 \%$ fructose was obtained using methanol as a solvent, while using water as a solvent the yield was $5 \%$. $\mathrm{Xu}$ et al. [32] incorporated iron in the beta zeolite and obtained $22 \%$ fructose yield using water as a solvent. Xia et al. [33] incorporated iron in different proportions in the beta zeolite, and the sample containing the smallest molar ratio showed the best result, as it happened in the present study.

\section{CONCLUSIONS}

The experiments of synthesis with TEAOH as a structure-directing agent (SDA) successfully formed the structure of the high-silica ZSM-12, but in this system, the addition of tin prevented the formation of the Sn-ZSM-12 zeolite. Therefore, TEABr was used as SDA, then again, the syntheses of high-silica ZSM-12 zeolite without and with tin incorporation were not effective. When the MTEACl was used as SDA, high-silica ZSM-12 structure was formed only with the incorporation of tin. Among the samples containing Sn, it was observed that the material with the highest degree of crystallinity was the one obtained with the $\mathrm{Sn} / \mathrm{Si}$ molar ratio of 0.005 . The increasing of the $\mathrm{Sn} / \mathrm{Si}$ ratio in the synthesis gel caused a reduction in the degree of crystallinity of the sample obtained. This was evidenced by the decrease in the intensity of the diffraction peaks, indicating that the incorporation of $\mathrm{Sn}$ in the ZSM-12 
zeolite structure is a difficult process, being possible only in low $\mathrm{Sn} / \mathrm{Si}$ molar ratios. The calcination of the samples containing the contamination by magadiite caused the disappearance of the diffraction peaks related to this phase indicating the decomposition of magadiite and formation of amorphous materials. The high-silica ZSM-12 zeolite synthesized in this study presented a typical surface area of the conventional ZSM-12 zeolite reported in the literature. The samples containing tin presented a reduction of surface area, external area, and microporous area in relation to ZSM12. The thermal analysis indicated that the decomposition reaction of the TEAOH and MTEACl occurred in a single step, whereas the removal of water on the external surface and inside the pores of the zeolite occurred differently in the high-silica ZSM-12 zeolite and the samples containing tin. This was attributed to the higher hydrophobicity of high-silica zeolite. The highest glucose conversions were observed at the longest reaction time, indicating that the reaction may not yet have reached equilibrium. However, increasing the tin concentration in the catalysts led to a reduction in glucose conversion.

\section{REFERENCES}

[1] J.P. Lange, E.V.D. Heide, J.V. Buijtenen, R. Price, ChemSusChem 5 (2012) 150.

[2] M. Moliner, Y. Román-Leshkov, M.E. Davis, Proc. Nat. Acad. Sci. 107 (2010) 6164.

[3] L. Hu, X. Tang, Z. Wu, L. Lin, J. Xu, N. Xu, B. Dai, Eng. J. 263 (2015) 299.

[4] H.L. Wang, ChemCatChem 6 (2014) 728.

[5] M. Zakrzewska, E. Bogel-Łukasik, R. Bogel-Łukasik, Chem. Rev. 111, 2 (2011) 397.

[6] F.N.D.C. Gomez, L.R. Pereira, N.F.P. Ribeiro, M.M.V.M. Souza, Braz. J. Chem. Eng. 32 (2015) 119.

[7] C. Kassargy, S. Awad, G. Burnens, G. Upreti, K. Kahine, M. Tazerout, Appl. Catal. B 244 (2019) 704.

[8] D. Masih, S. Rohani, J.N. Kondo, T. Tatsumi, Microporous Mesoporous Mater. 282 (2019) 91.

[9] M. Xiang, D. Wu, Chem. Eng. J. 369 (2019) 180.

[10] R. Chen, C. Yang, Q. Zhang, B. Zhang, K. Deng, J. Catal. 374 (2019) 297.

[11] D.N. Gerasimov, E.V. Kashin, I.V. Pigoleva, I.A. Maslov, V.V. Fadeev, S.V. Zaglyadova, Energy Fuels 33, 4 (2019) 3492 .

[12] I. Delidovich, R. Palkovits, ChemSusChem 9 (2016) 547.
[13] C. Moreau, R. Durand, A. Roux, D. Tichit, Appl. Catal. A 193 (2000) 257.

[14] N. Deshpande, N.L. Pattanaik, M. Whitaker, C. Yang, L. Lin, N.A. Brunelli, J. Catal. 353 (2017) 205.

[15] G. Li, E.A. Pidko, E.J.M. Hensen, Catal. Sci. Technol. 4 (2014) 2241.

[16] C. Paris, N. Martín, J.M. Triguero, M. Moliner, A. Corma, New J. Chem. 40 (2015) 4140.

[17] A. Mitra, C.W. Kirby, Z. Wang, L. Huang, H. Wang, Y. Huang, Y. Yan, Microporous Mesoporous Mater. 54, 2 (2002) 175.

[18] N.K. Mal, A. Bhaumik, R. Kumar, A.V. Ramaswamy, Catal. Letters 33 (1995) 387.

[19] Int. Zeolite Ass., www.iza-online.org, acc. 26/07/2019. [20] K. Yoo, K, Ruhnaz, S. Gopal, P.G. Smirniotis, M. Gangoda, R.N. Bose, Microporous Mesoporous Mater. 60, 3 (2003) 57.

[21] N.K. Mal, A. Bhaumik, V. Ramaswamy, A.A. Belhekar, A.V. Ramaswamy, Stud. Surf. Sci. Catal. 94 (1995) 317.

[22] J.A. Jennings, S. Parkin, E. Munson, S.P. Delaney, J.L. Calahan, M. Isaacs, K. Honge, M. Crocker, RSC Adv. 7, 42 (2017) 25987.

[23] A. Bayu, S. Karnjanakom, K. Kusakabe, A. Abudula, G. Guan, Chinese J. Catal. 38, 3 (2017) 426.

[24] M. Kasunič, J. Legiša, A. Meden, N.Z. Logar, A.M. Beale, A. Golobič, Microporous Mesoporous Mater. 122, 3 (2009) 255.

[25] M. Počkaj, A. Meden, N.Z. Logar, M. Rangus, G. Mali, I. Lezcano-Gonzalez, A.M. Beale, A. Golobič, Microporous Mesoporous Mater. 263 (2018) 236.

[26] N. Knudsen, E.K. Andersen, I.G.K. Andersen, P. Norby, E. Skou, Solid State Ion. 61, 3 (1993) 153.

[27] D.E. Tsaplin, D.A. Makeeva, L.A. Kulikov, A.L. Maksimov, E.A. Karakhanov, Russ. J. Appl. Chem. 91, 12 (2018) 1957.

[28] A. Pourahmad, G. Mehmandoust, J. Inorg. Organomet. Polym. Mater. 28, 6 (2018) 2213.

[29] N. Masoumifard, S. Kaliaguine, F. Kleitz, Microporous Mesoporous Mater. 227 (2016) 258.

[30] S. Saravanamurugan, M. Paniagua, J.A. Melero, A. Riisager, J. Am. Chem. Soc. 135, 14 (2013) 5246.

[31] R. Bermejo-Deval, M. Orazov, R. Gounder, S. Hwang, M.E. Davis, CS Catal. 4, 7 (2014) 2288.

[32] S. Xu, L. Zhang, K. Xiao, H. Xia, Carbohydr. Res. 446447 (2017) 48.

[33] H. Xia, H. Hu, S. Xu, K. Xiao, S. Zuo, Biomass Bioenergy 108 (2018) 426.

(Rec.02/10/2019, Rev.05/02/2020, Ac. 07/02/2020) 